\title{
Daniela Serna: del texto en expansión a los límites de la forma*
}

DOI: 10.17230/co-herencia.17.32.13

\author{
Fernando Mora Meléndez** \\ fmora@eafit.edu.co
}

\begin{abstract}
Resumen Daniela Serna (Medellín, 1991) investiga y crea sobre el tránsito que se produce entre el objeto verbal de origen literario y el artefacto visual de carácter plástico y estético. Su obra expande la idea de la literatura formal, donde las dimensiones temporales y sensoriales se experimentan en la imaginación del lector, para proponer poemas visuales en los cuales propicia una experiencia de sentido que amplifica o diluye los límites de lo posible. En esta reseña se abordan un conjunto de obras, cuyo eje central permite múltiples lecturas, tamizadas por una reserva de signos ideológicos, políticos y estéticos en los cuales la artista inscribe su obra, y que permiten interrogar la relación entre el mundo ficcional representado y la representación que el lector/espectador realiza.
\end{abstract}

\section{Palabras clave:}

Arte colombiano, arte conceptual, poesía visual, concretismo, arte palabra, literatura comparada.

\section{Daniela Serna: From the Expanding Text to the Limits of Shape}

\begin{abstract}
Daniela Serna (Medellín, 1991) conducts research and creates works of art on the transition between a literary verbal object and a visual artifact of a plastic and esthetic nature. Her work expands on the idea of formal literature, where the temporal and sensorial dimensions are in the reader's imagination, to propose visual poems that encourage an experience of meaning that augments or blurs the limits of what is possible. This review deals with a set of works, the core topic of which enables multiple readings, which are carefully selected using a collection of ideological, political, and esthetic signs that the artist brings into her work and that allow us to question the relationship between the represented fictional world and the reader or observer's representation.
\end{abstract}

\section{Keywords:}

Colombian art, conceptual art, visual poetry, concretism, word art, comparative literature.
"Este texto hace parte de la investigación Viejos signos/nuevas rotaciones. Espacio, tiempo y acción en la poesía experimental en América Latina, proyecto iniciado en 2019 y adscrito al Departamento de Humanidades de la Universidad EAFIT.

** Magíster en Dramaturgia y Dirección de la Universidad de Antioquia. Profesor del Departamento de Comunicación Social de la Universidad EAFIT, Medellín, Colombia. ORCID: 0000-0003-4859-2394 


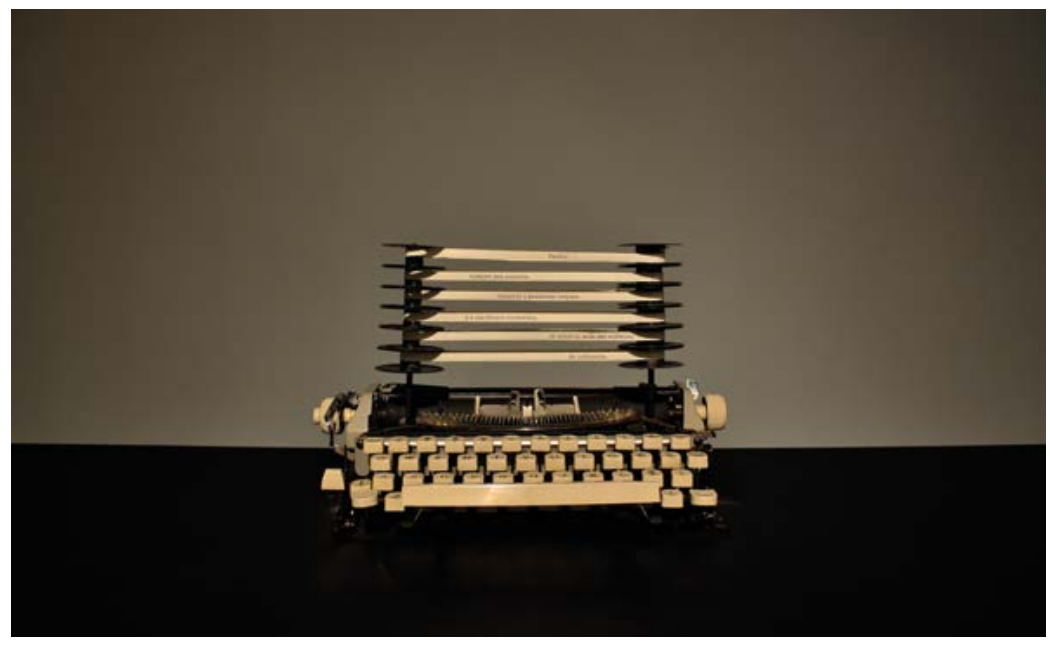

Daniela Serna. Entre líneas, 2012. Instalación: objetos, motores, papel. Dimensiones variables. Textos: Jorge Luis Borges. 
Quizá los dioses no me negarían el hallazgo de una imagen equivalente, pero este informe quedaría contaminado de literatura, de falsedad. Por lo demás, el problema central es irresoluble: la enumeración, siquiera parcial, de un conjunto infinito. En ese instante gigantesco, he visto millones de actos deleitables o atroces; ninguno me asombró como el hecho de que todos ocuparan el mismo punto, sin superposición y sin transparencia. Lo que vieron mis ojos fue simultáneo: lo que transcribiré, sucesivo, porque el lenguaje lo es. Algo, sin embargo, recogeré.

Jorge Luis Borges, "El Aleph”.

En la obra Desconcierto (2015) de Daniela Serna (1991) una máquina de escribir se desarma en su interior. Sus múltiples barras de tipos, como huesos, sostienen una nueva armazón que significa otra cosa; surge como un entramado de palancas cuya función es acoplarse para liberarse en formas que se asemejan a las ramas de un árbol. En esta obra la artista desarma el texto que aún no existe, o que es una posibilidad en los tipos de la máquina, y propone una nueva narración. En esta operación el dispositivo de escritura pierde su funcionalidad y adquiere un hálito de vida, una nueva esencia: es árbol, rama o rizoma. En esta pieza, el ente se despliega para compararse con el hombre que imagina y crea. Es un artefacto industrial que ha perdido utilidad: ya no es herramienta, no es máquina, y alude acaso a la posibilidad de ser organismo.

Otra indagación sobre los entresijos de la máquina y la escritura se configura mediante un objeto intervenido: Entre líneas (2012), una instalación de la artista en la que los carretes de cinta de la máquina levitan y juegan con el sentido de algunos textos de Borges. En el tránsito entre un objeto verbal, de origen literario, y un artefacto visual, de carácter plástico y estético, la artista elude la idea de ilustrar las imágenes que el texto literario le provoca como lectora; reafirma la idea de que nunca se lee de igual modo un mismo texto: una línea de signos, a la manera del río de Heráclito, se torna cada tanto en una vivencia renovada que amplifica los límites de lo posible, al menos cuando se trata de un fragmento literario de los que pretenden no solo representar un mundo sino quizá significarlo. Así, Serna compone una deriva de sentido que interroga, trastoca o reinventa la intención significante de la escritura de referencia. Dicho 


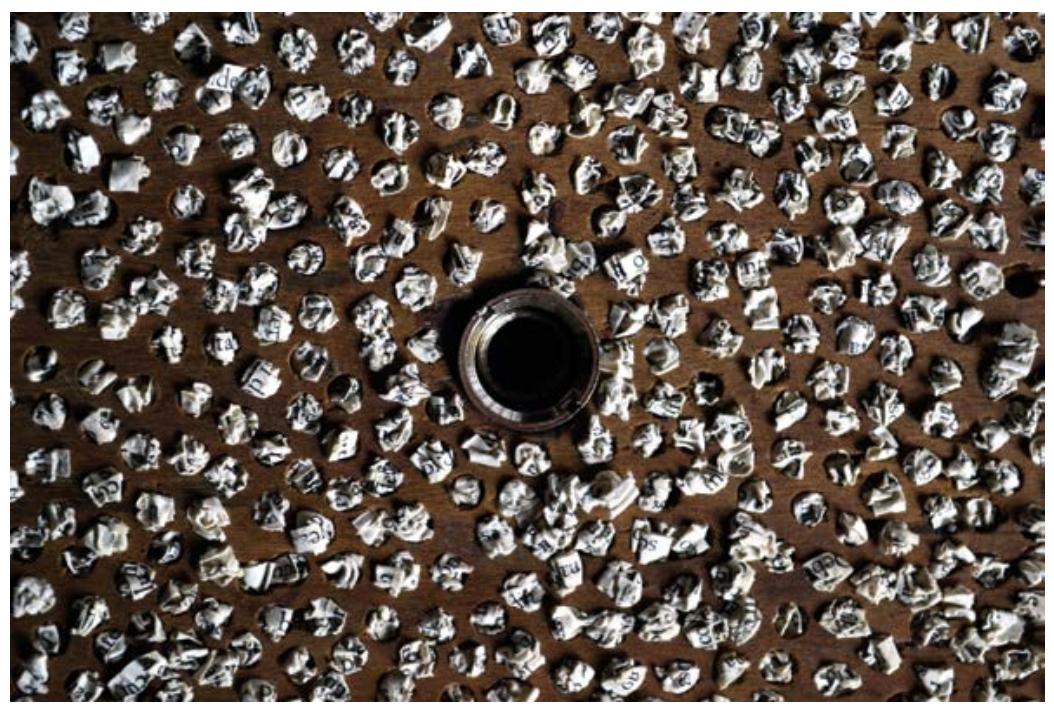

Daniela Serna. De la serie: Construyendo un elefante blanco, 2011-2016. Madera perforada, hojas de libro. Dimensiones pupitre: $77 \times 70 \times 48 \mathrm{~cm}$. 
procedimiento, al distender los límites semánticos de la obra literaria, brinda apertura a la coexistencia de múltiples lecturas, tamizadas por una reserva de signos ideológicos, políticos y estéticos. En este terreno, acaso difuso e inaprensible, el de la imagen que proyectan los objetos, se ubica, como se sabe, la experiencia estética del espectador.

Los trabajos de la artista surgen, en parte, de un ejercicio de reinvención como lectora de relatos ficcionales. En este sentido, su amplio registro formal y conceptual propone una reflexión sobre las diversas instancias que recorre un texto, incluso desde antes de su composición, forma de impresión y materialidad como libro, hasta los periplos de circulación en el ámbito escolar o en el espacio íntimo donde la artista relee e interpreta a escritores del canon latinoamericano como Borges, Cortázar, García Márquez o Clarice Lispector.

Sus obras a menudo configuran una síntesis entre el valor formal y la idea o pretexto temático que sus piezas evocan. Tal duplicidad se manifiesta en los proyectos Entre líneas (2012), Desconcierto (2015) y Línea recta (2016). En ellos se interviene el objeto industrial, una máquina de escribir, para transformarlo en una metáfora de los conceptos relacionados con la propia naturaleza de los textos narrativos, como el de la imposibilidad de traducir un mundo multidimensional en la forma unidimensional de la palabra escrita, por ejemplo, o el de la relación del tiempo de la lectura con los soportes donde el texto se recorre o donde se verifica el encuentro entre el mundo ficcional representado y la representación que realiza el lector.

En Linea recta (2016) los carretes de la máquina de escribir se levantan para mostrar, en lugar de la antigua línea entintada, una cinta de papel que circula mediante un mecanismo incorporado y que hace correr los fragmentos de Saint-Exupéry. De un modo similar sucede en otras máquinas de la serie Entre líneas (2012) donde la autora escoge pedazos de los textos originales con la intención persistente de apropiarse de la cita de autor e insertarla en el espacio expositivo de sus máquinas textuales. Las anteriores propuestas pueden ligarse con la tendencia contemporánea denominada artepalabra desarrollada como disciplina y cubierta en diferentes facetas por la crítica e historia del arte contemporáneo, como en el texto de Ana María Guash (2005), quien afirma: 
La consideración de palabras como arte, lo que en el entorno del arte conceptual se denominó word-art (arte-palabra), implica que el texto (la palabra en tanto elemento discursivo en un contexto literario) y el titulado (la palabra en tanto elemento gráfico en un contexto visual) se transformaron en "logos", en palabras-objeto sin contexto y sin connotación literarias, si bien en algunos casos los textos combinan la visualización de un vasto espacio con un acto que de por sí no tendría significación (p. 183).

La obra de Daniela Serna también se inscribe en un proyecto de investigación literaria y plástica que realizó en Brasil, durante sus estudios de literatura comparada. Bajo la influencia de la poesía neoconcreta (que pregonaron los poetas y artistas brasileros del movimiento Noigrandes, como Decio Pignatieri y Haroldo de Campos), aplica procedimientos técnicos y estéticos que le permiten explorar el uso de las palabras como objetos, su relación con el espacio, el soporte, la experimentación poética y sensorial, el sentido de ironía y disrupción, sin dejar de lado los referentes de la tradición literaria.

Aunado a esto, y como aparición temprana en la obra de Serna, se evidencia un interés por aquello que Roger Chartier (2006) denomina las condiciones de publicación de un texto o la materialidad misma de los soportes, que a menudo se soslayan a la hora de interpretar una obra y que están insertos en la definición de la sensibilidad propia del instante histórico:

Contra semejante abstracción de los discursos, es conveniente recordar que la producción, no sólo de los libros, sino de los propios textos, es un proceso que, más allá del gesto de la escritura, implica diferentes momentos, diferentes técnicas, diferentes intervenciones: las de los copistas, los libreros editores, los maestros impresores, los cajistas (o componedores en la lengua del Siglo de Oro), los correctores [...] El proceso de publicación, cualquiera que sea su modalidad, siempre es un proceso colectivo, que implica a numerosos actores y que no separa la materialidad del texto de la textualidad del libro (2006, p. 3).

En Ovo (2019) se exploran fragmentos de un cuento de la escritora Clarice Lispector, "O ovo e a Galinha". La obra es una instalación en la cual dos motores hacen girar unos carretes que exhiben un rollo de papel inscrito solo con la letra O. Para ello, Serna elimina del relato de Lispector todas las letras, excepto las “oes”. Luego une las once páginas que componen el relato y las pone a rotar mediante este mecanismo. Así, el texto deja de percibirse como una sucesión diacrónica de signos 


\section{Ooo}

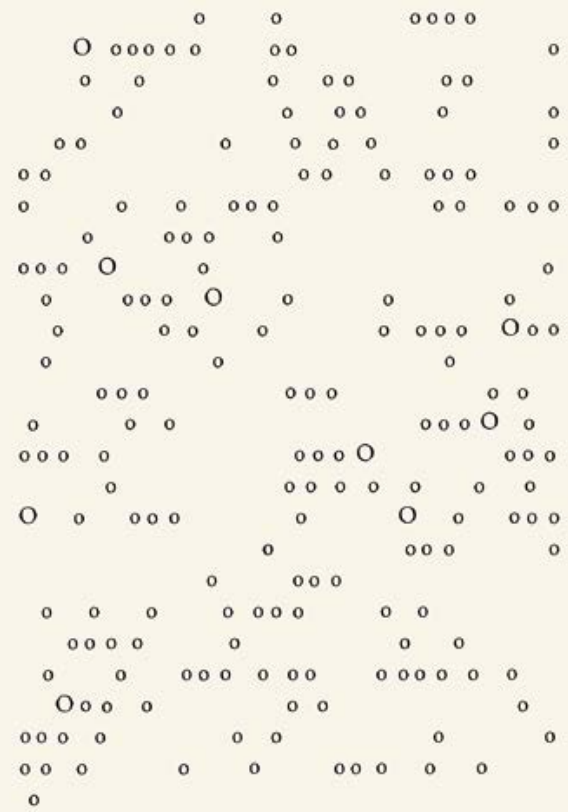

Daniela Serna. Ovo, 2019. Instalación: motor, carretes, papel.

Dimensiones: $120 \times 21 \times 12 \mathrm{~cm}$. 
articulados. Ya no es lenguaje literario y, sin embargo, puede leerse. El soporte y el giro incesante sugieren otras formas -como el monstruo en la nube-, las letras son formas trastocadas, son dibujo y expresión, grito de arbitrariedad: no hay signo lingüístico, no hay semejanza: ¿qué nombramos?, nos interroga la artista.

En su instalación Perífrasis (2018) el soporte es una estructura de metal que forma un tablero cuasicurvo con tres hileras que contienen diez relojes giratorios cada uno. En cada reloj se reemplazaron los números por letras de una frase; de esta manera, el mecanismo hace que en cada minuto se produzca una imagen o línea textual diferente durante un ciclo de 24 horas, lo que permite la combinación aleatoria de letras, para transmutar, recombinar y deconstruir el fragmento original en 1440 variaciones. Y aunque en la mayoría de resultados las frases resultan ilegibles, en los términos sintagmáticos del idioma las secuencias de signos resultantes se convierten en imágenes que cobran valor como presencias visuales que mutan con el paso del tiempo. La relación entre la velocidad de cambio de las letras y la de la lectura, por parte del espectador, fijan en este la percepción temporal de su obra. No es casual que varios de los fragmentos que extrae de sus escritores preferidos aludan a la dimensión temporal de la existencia, en consonancia con la definición machadiana de la poesía: "Ni mármol duro y eterno,/ ni música ni pintura,/ sino palabra en el tiempo" (1974, p. 703). Las citas sobre el tiempo aparecen -ruedan en las máquinas- de un modo más o menos elusivo, como sucede en su Dispositivo de lectura (2015), obra en la que un péndulo, como en el poema visual de Decio Pignatari, activa el mecanismo que pone a girar cinco carretes con líneas de texto.

De esta manera, los proyectos de la artista se vinculan con los procedimientos que el arte conceptual y la literatura transitaron por igual, tanto en las primeras como en las segundas vanguardias del siglo xx. En ellas la dimensión sonora y plástica del lenguaje escrito rebasa su interés semántico o sintáctico, como anota José A. Sánchez:

Joyce había intentado la elaboración de un lenguaje universal basado en la música significante de las palabras. No se acepta la pérdida de la relación semántica sin más: se trata de construir otros modos de significar, que se alejan de la convención y de la evidencia, que se extienden más allá de la palabra, a todo el libro, o que se concentran en una letra, sin dejar por ello de existir sin ningún caso (1992, p. 69). 


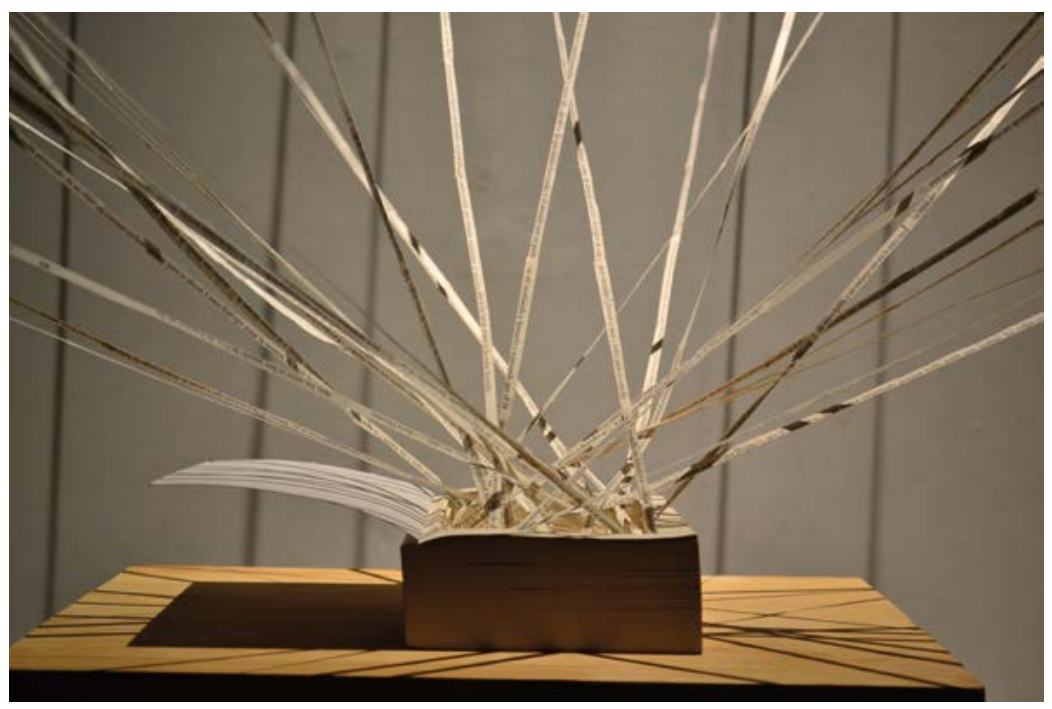

Daniela Serna. Línea de fuga, 2011. Instalación: Libro intervenido, mesa de madera. Dimensiones: $250 \times 250 \mathrm{~cm}$. 
Dicha indagación por los soportes de memoria en el libro ya aparece en su secuencia de imágenes titulada Una vez en una isla (2011). En la serie se reúnen viejos textos de literatura popular: manuales de ocultismo, tratados de metafísica, algún folletín romántico, un texto de cosmología y otros cursillos de espiritualidad y de ayuda para el éxito. El conjunto parece un registro de la sensibilidad particular y a la vez universal de una época, en distintas lenguas, con los datos intactos para un bibliófilo, o incluso para un sociólogo de la lectura. Y más allá de la relevancia de los títulos y temas afines a cierto orden sibilino, atrae la proliferación de marcas personales, restos orgánicos de insectos, flores, fotografías y notas de lectores anónimos: huellas y vestigios de tiempos y atmósferas que nos remiten a una intimidad y temporalidad suspendidas.

En la obra Matriz (2017) el signo de naturaleza lingüística aparece objetivado en una serie de letras tridimensionales, de grafito y resina, dispuestas en hileras, a la manera de los antiguos moldes de linotipias, solo que ahora los fragmentos conforman otra sintaxis invertida o dislocada. Tal dispositivo le permite materializar en objetos escultóricos los signos impresos de la lengua y disponerlos en otro ámbito distinto al del soporte escrito. En este caso, el pretexto es Jorge Luis Borges, autor al que, por cierto, no dejaron de fascinarle los libros en cuanto objetos de una substancia al mismo tiempo material e imaginaria, memoriosa e incorpórea.

En similar dimensión temática, la escultura Construyendo un elefante blanco (2011) replica las marcas escolares en un pupitre. Esta vez Serna ha creado sus propias señales en la superficie de la madera: son diminutos agujeros en los que introduce fragmentos del texto de Saint-Exupéry en bolitas de papel. La evocación de la lectura de parvulario dispone el libro en el ámbito de la lectura pública, la del régimen educativo reglado por ciertas matrices interpretativas del texto literario. Igualmente, en la misma dirección se toma el Diccionario de la Real Academia, árbitro supremo de la corrección idiomática, para expurgarlo de las páginas y mostrarlo como vestigio quemado, una especie de reliquia rescatada de un incendio de palabras. Esta obra, Cremáre (2010), remite a las reflexiones de Roland Barthes (1977), en su Lección inaugural de semiología sobre la lengua como estructura autocontrolada: 


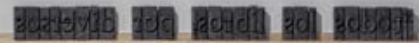

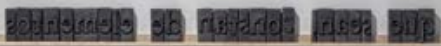

Cy

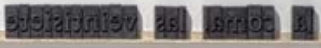

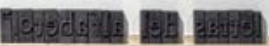

Daniela Serna. Matriz, 2017. Instalación: grafito, resina, madera.

Dimensiones variables. 
El lenguaje es una legislación, la lengua es su código. No vemos el poder que hay en la lengua porque olvidamos que toda lengua es una clasificación, y que toda clasificación es opresiva: ordo quiere decir a la vez repartición y conminación. Como Jakobson lo ha demostrado, un idioma se define menos por lo que permite decir que por lo que obliga a decir (p. 118).

La exploración plástica del signo lingüístico como insumo para provocar juegos de lenguaje fue una idea que activó a buena parte de los artistas que fundaron el llamado neoconcretismo en América Latina. Bajo el designador de poesía visual se engloban trabajos de grupos de artistas en Brasil, Chile y Argentina. A dichas indagaciones sobre el lenguaje se vinculan diversos nombres contemporáneos, como Elida Tessler, Luis Camnitzer y Jorge Méndez Blake, artistas que Serna menciona como antecedentes de su investigación. Los neoconcretistas, que aparecen de manera simultánea en Europa y América, se emparentan de algún modo en las pesquisas que la artista reúne como trabajo procesual en su obra Narrativas, objetos y derivas.

A propósito, Serna declara, a manera de enunciado estético, su relación con las palabras:

Asumo los textos escritos como un material plástico, maleable, mutable, transformable; no solo desde su condición como imagen, sino también como signo lingüístico, en su versatilidad y flexibilidad semántica y las relaciones sociales y culturales que involucran. Es a través de distintos objetos, soportes y mecanismos que mi proceso artístico propone señalar, alterar y resignificar las múltiples maneras de acceder y entender los textos (CIFO, 2018, p. 81).

Por otra parte, de la condición existencial del tiempo que gravita y genera reflexiones se discurre hacia el imperativo social sobre el uso del tiempo en el ámbito laboral, además de otras consignas dominantes, las mismas que aparecen y desaparecen de manera irónica en obras como Derivaciones (2013), una pieza mecánica que trocea apartes del discurso "Antioquia produce genios" del filósofo colombiano Fernando González. El uso del fragmento en estas dos últimas, al descomponer la cadena significante del ensayo original, genera otros efectos de sentido, a manera de consignas dotadas de gracia, sarcasmo y sentido poético.

Tal empleo de las citas en las máquinas de Serna está en consonancia con la idea de apropiación en el arte conceptual 


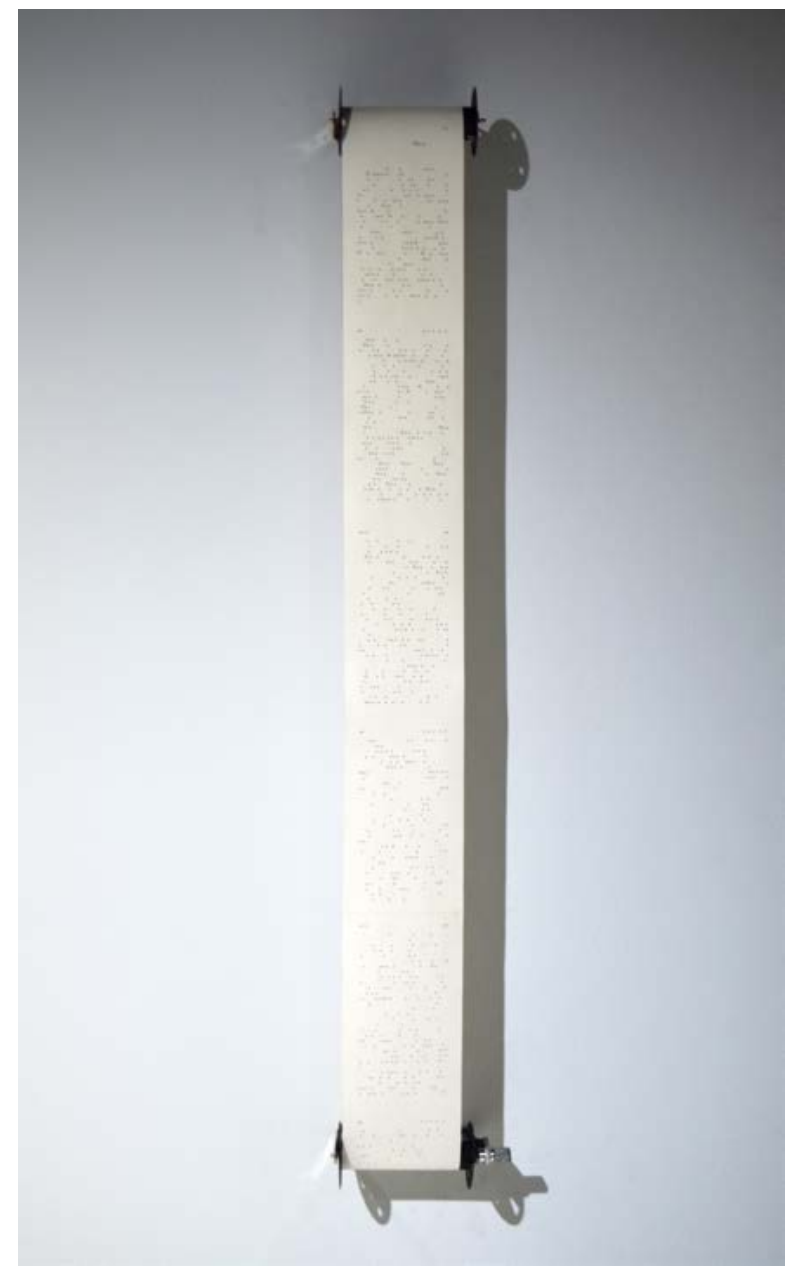

Daniela Serna. Ovo, 2019. Instalación: motor, carretes, papel.

Dimensiones: $120 \times 21 \times 12 \mathrm{~cm}$. 
y en la corriente neoconcreta. Tanto los artistas del word-art norteamericano, como los poetas visuales del Brasil, a menudo retoman frases tópicas o lemas mediáticos de alguna ideología para trastocar su sentido primario con los consecuentes efectos paródicos y revulsivos. En su caso, el solo hecho de elegir partes y ubicarlas en otro soporte, se convierte en un intento por privilegiar el gusto por la lectura del fragmento antes que por la totalidad hegemónica que impone el sentido del texto completo. La intención puede ser disruptiva o transgresora, como sucede en Derivaciones (2013), pero también un juego metatextual, como ocurre en Ojos de perro azul (2019). En este último, se eligen frases de una página del cuento de García Márquez para que aparezca un poema nuevo, a manera de una deriva inesperada, donde adquiere relevancia el poema visual que forman las frases en el blanco de la página.

De otro lado, la obra de Daniela Serna dilucida y controvierte el objeto libro y su producción industrial, el papel, la máquina, el lugar del escritor y, finalmente, el acto de leer, es decir, la compostura mental que este exige, a saber, seguir una línea fija, diacrónica, en la que cada lector impondría su ritmo. Sus máquinas se activan en contra de las consignas del uso del tiempo, de la lectura rápida y el dictamen de apresar pronto el significado; o se anula la actitud paciente, degustada, sin la cual no es posible percibir los atributos poéticos de una escritura, aquello sobre lo que Roland Barthes elucubró en El placer del texto. En esta dirección, la necesidad de un lector moroso, uno que lee menos, pero tal vez mejor, se torna un motivo insistente en varias de sus obras, desde las más tempranas, como la videoescultura En-negro (2011): allí los libros dispersos en una mesa se han cubierto de una especie de magma negro que los torna pétreos e inaccesibles, mientras que lo único vivo en aquella superficie son los ojos en movimiento de un lector que asoman en un par de pantallas diminutas. La mirada parece recorrer una y otra vez la línea interminable del lenguaje.

La obra de Daniela Serna remite a un universo de posibilidades semánticas, visuales y poéticas en donde el "cuerpo textual" que compone trastoca y alienta otra percepción, como ocurre en la instalación Línea de fuga (2011): un libro se desarma en su interior, abre 

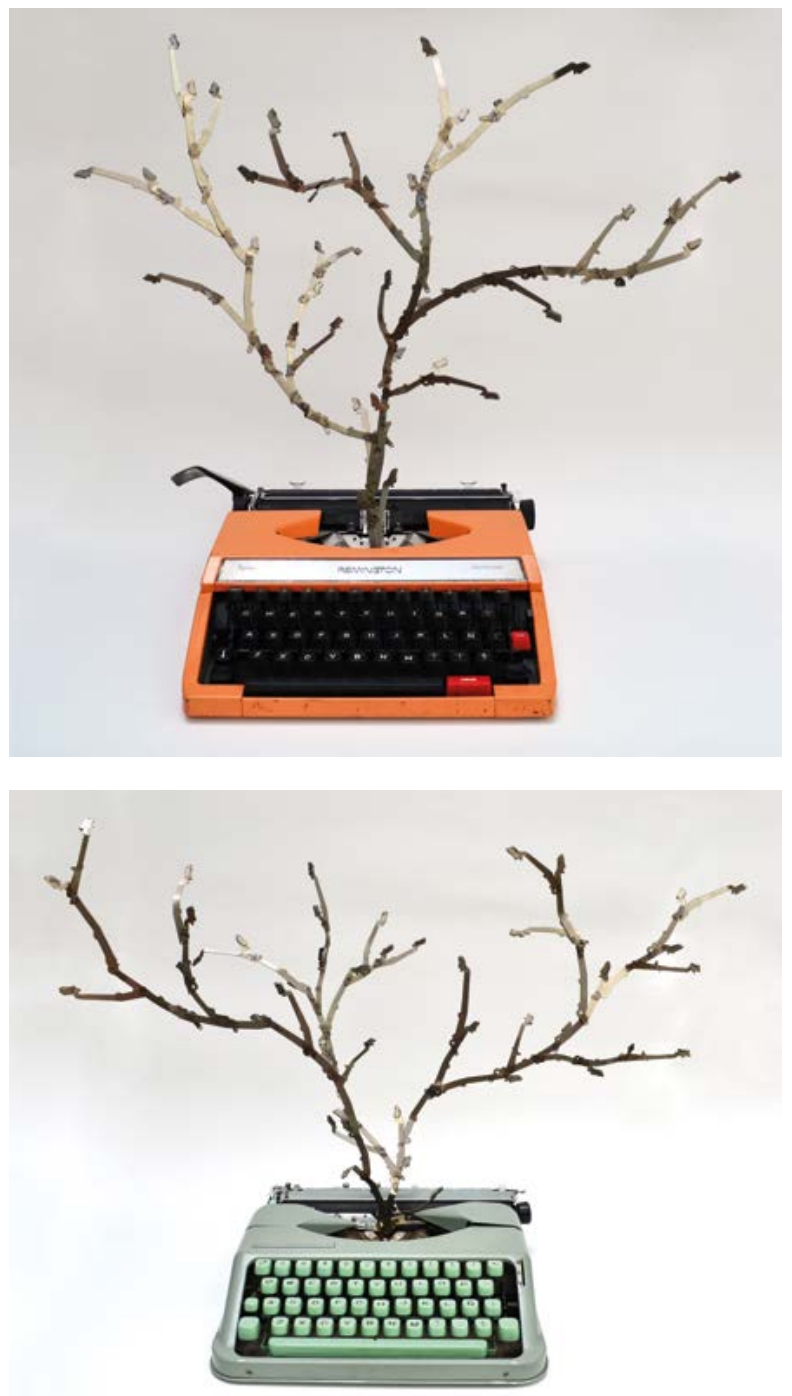

Daniela Serna. De la serie: Desconcierto, 2015. Máquinas de escribir, barras de tipos. Dimensiones $45 \times 53 \times 33 \mathrm{~cm}$. 
su canto y lanza sus frases en finas cintas que se proyectan como rayos de tinta. Esta es quizá esa máquina de "alambres y cajones vacíos" con la que la artista nos muestra que lo allí contenido se ha fugado hacia diversos destinos. Las palabras, los tipos, las máquinas y las letras se han sublevado, afloran hacia horizontes imprevistos de significación 【

\section{Referencias}

Barthes, R. (1993). Lección inaugural de la cátedra de semiología lingüística. En El placer del texto (pp. 111-150). Siglo XXI.

Borges, J. (1997). El Aleph. Alianza.

Chartier, R. (2006). Materialidad del texto, textualidad del libro. Orbis Tertius: Revista de Teoría y Crítica Literaria, 11(12), 1-15. https://bit. ly/2WuGBL5

Cisneros Fontanals Art Foundation (CIFO). (2018). Strategic Inmersions: First Stop 2018. Grants $\mathcal{E}$ Comissions Program Exhibition. Cisneros Fontanals Art Foundation.

Guash, A. (2005). El arte último del siglo xx. Alianza.

Machado, A. (1974). Obras: Poesía y prosa. Losada.

Sánchez, J. (1992). Dramaturgias de la imagen. Ediciones de la Universidad de Castilla-La Mancha. 